\title{
PENGARUH KOEFISIEN GESEKAN PADA PROSES MANUFAKTUR
}

\author{
Tri Widodo Besar Riyadi \\ Jurusan Teknik Mesin, Universitas Muhammadiyah Surakarta \\ Email: tri wbr@yahoo.com
}

\begin{abstract}
ABSTRAKSI
Pada proses manufaktur, faktor gesekan antara permukaan benda kerja dengan die memegang peranan yang sangat penting karena akan menentukan besar beban dan gaya yang dibutuhkan selama penekanan, umur peralatan, formability benda kerja, dan kualitas produk. Selain itu, faktor gesekan juga sangat penting dalam perhitungan analitik dan numerik terhadap tegangan, regangan, dan dalam memprediksi gaya penekan secara empiris. Meskipun mekanika gesekan antar permukaan sangat rumit, tetapi sangatlah penting untuk mendefinisikan seberapa besar nilainya, dalam hal ini berupa faktor gesekan atau koefisien gesekan. Beberapa pengujian telah dilakukan untuk mengetahui seberapa besar koefisien gesek, diantaranya adalah ring compression test. Pada penelitian ini akan dipelajari bagaimana pengaruh koefisien gesek terhadap proses manufaktur khususnya pada proses ekstrusi. Penelitian dilakukan secara paralel dengan eksperimen dan metode elemen hingga yang menggunakan software ABAQUS. Hasil penelitian menunjukkan bahwa semakin besar nilai koefisien gesek, maka gaya penekanan akan semakin tinggi.
\end{abstract}

Kata-kata kunci: koefisien gesekan, ekstrusi

\section{PENDAHULUAN}

Faktor gesekan tidak hanya mengubah besarnya gaya penekanan tetapi juga sangat berkaitan langsung dengan kualitas produk yang dihasilkan pada proses manufaktur. Gaya gesekan adalah berbanding lurus dengan kondisi pelumasan pada permukaan benda kerja yang bersinggungan. Metode untuk memperkirakan besar koefisien gesekan pada dua permukaan yang bersinggungan pernah diusulkan oleh beberapa peneliti. Wagnerer dan Wolf (1994) menggunakan data hasil simulasi dan eksperimen untuk memperoleh koefisien gesekan pada proses tempa (forging). Sebuah metode baru juga pernah diusulkan oleh Nakamura dan Bay
(1996) dalam dua tulisannya, dimana koefisien gesekan dapat diperkirakan tanpa membutuhkan pengukuran terhadap beban penekanan dan flow stress dari benda kerja. Hsu dan Lee (1995, 1997) mengkombinasikan elemen hingga benda rigid-plastic untuk menyelidiki distribusi gesekan pada proses maufaktur. Keduanya kemudian menggunakan metode yang sama dalam mengembangkan model gesekan yang realistis yang mencakup variabel viskositas, dan kekasaran permukaan pada simulasi proses ekstrusi dengan dies miring. Salah satu pengujian yang paling banyak digunakan untuk menentukan koefisien gesekan adalah dengan menggunakaan ring compression 
test. Pada pengujian ini, geometri dies dan aliran material sangat sederhana, dan tekanan yang dibutuhkan juga relatif kecil, serta permukaan yang dihasilkan selama proses deformasi juga cukup kecil. Dengan demikian, pada pengujian ini, karakterisitik gesekan tidak dapat dievaluasi (Shen, 1992).

Pada penelitian ini, pengaruh koefisien gesekan pada proses manufaktur akan diteliti dengan menggunakan data hasil simulasi dan eksperimen. Pengujian dilaksanakan pada proses ekstrusi dengan material timah hitam. Material ini meskipun beracun tetap dipilih karena hanya membutuhkan gaya penekanan yang relatif kecil sesuai dengan keterbatasan kapasitas penekanan dari peralatan dan mesin yang tersedia.

\section{TINJAUAN PUSTAKA}

Gambar 1 menunjukkan sketsa proses ekstrusi (forward extrusion). Bakshi dan Jooybari (2003) menunjukkan bahwa besar gaya ekstrusi yang dibutuhkan untuk menghasilkan deformasi adalah sebagai berikut:

$$
F_{t}=F_{f c}+F_{f d}+F_{d d}
$$

dengan $F_{t}$ adalah jumlah keseluruhan gaya ekstrusi, $F_{f c}$ gaya gesekan antara benda kerja dan kontainer, $F_{f d}$ gaya gesekan antara benda kerja dan dies, serta $F_{d d}$ gaya deformasi dalam dies. Pada persamaan (1), jumlah gaya $F_{f d}$ dan $F_{d d}$ dapat diganti menjadi $F_{d}$.

$$
F_{t}=F_{f c}+F_{d}
$$

Gaya gesekan antara benda kerja dan kontainer dapat didefinisikan menjadi:

$$
F_{f c}=\tau \pi d_{0} L
$$

dengan $\tau$ tegangan geser antara benda kerja dan kontainer, $L$ panjang benda kerja dalam kontainer, dan $d_{0}$ diameter dalam kontainer.

Dengan substitusi persamaam (3) kedalam persamaan (2), maka jumlah total gaya ekstrusi adalah sebagai berikut:

$$
F_{t}=\tau \pi d_{0} L+F_{d}
$$

Tegangan geser dalam kontainer $\tau$ dapat didefinisikan sebagai fungsi dari faktor gesekan $(m)$ dan shear flow stress material $(k)$.

$$
\tau=m k
$$

\begin{tabular}{llll}
\hline 2 & Pengaruh & Koefisien & Gesekan terhadap Proses \\
Manufaktur & &
\end{tabular}




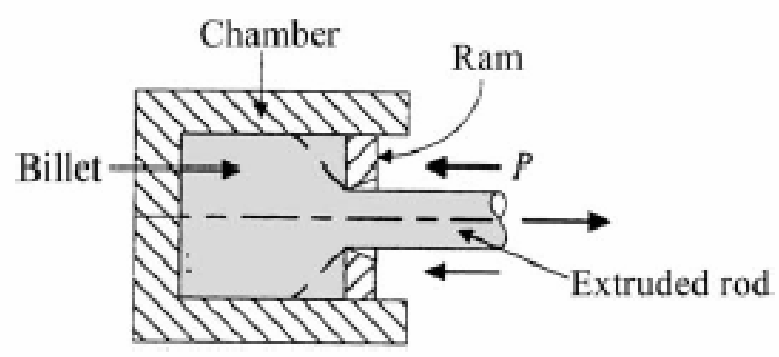

Gambar 1. Sketsa proses forward extrusion.

Menurut kriteria luluh Von Mises, $k$ sebanding dengan normal flow stress.

$$
k=\frac{\sqrt{3}}{3} \bar{\sigma}
$$

dengan $\bar{\sigma}$ adalah normal flow stress.

Dengan mengganti persamaan (5) kedalam persamaan (4), dan dengan menggunakan persamaan (6), maka:

$$
F_{t}=\frac{\sqrt{3}}{3} \pi m \bar{\sigma} d_{0} L+F_{d}
$$

Pada proses forward extrusion, gaya maksimum dicapai setelah benda kerja memenuhi isi kontainer (10). Setelah proses berlanjut, gaya Fd akan konstan, dan dengan makin berkurangnya panjang benda kerja dala kontainer, maka gaya gesekan akan makin menurun pula. Dengan demikian persamaan (7) dapat ditulis secara sederhana sebagai berikut:

$$
F_{t}=a \cdot L+F_{d}
$$

$$
\text { dengan } a=\frac{\sqrt{3}}{3} \pi m \bar{\sigma} d_{0}
$$

Karena $d_{0}$ konstan, dengan menganggap $m$ dan $\bar{\sigma}$ juga konstan, maka $a$ juga akan konstan, dan ketika $F_{d}$ mencapai nilai maksimumnya, maka persamaan (8) akan merupakan persamaan linier yang menyatakan bahwa dengan berkurangnya panjang benda kerja $L$, jumlah total gaya ekstrusi juga akan menurun secara linier.

\section{METODOLOGI PENELITIAN}

Penelitian dilakukan secara paralel antara program eksperimen dan simulasi. Pada proses eksperimen, desain peralatan adalah seperti terlihat pada gambar 2 sebagai berikut : benda kerja berbentuk silinder terbuat dari timah hitam dengan ukuran diameter $25.4 \mathrm{~mm}$ dan ketebalan $20.0 \mathrm{~mm}$. Dies mempunyai diameter $22.0 \mathrm{~mm}$ sehingga reduksinya adalah 0.25 . Meskipun timah hitam kurang sensitif terhadap peregangan pada suhu kamar, tetapi annealing tetap diperlukan untuk memperoleh ukuran butiran material yang halus. 


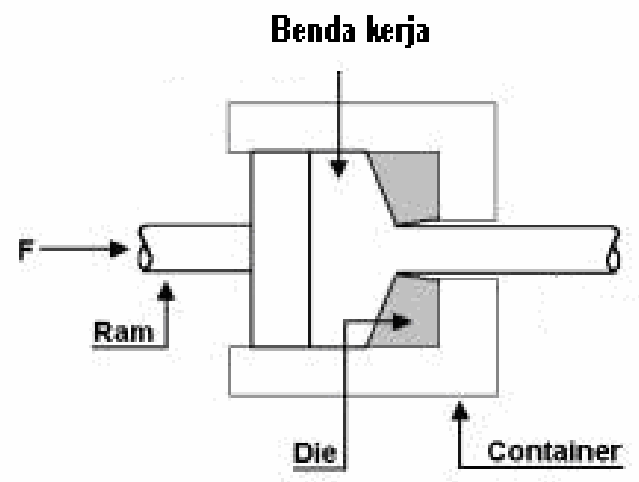

Gambar 2. Sketsa desain alat ekstrusi dan benda kerja

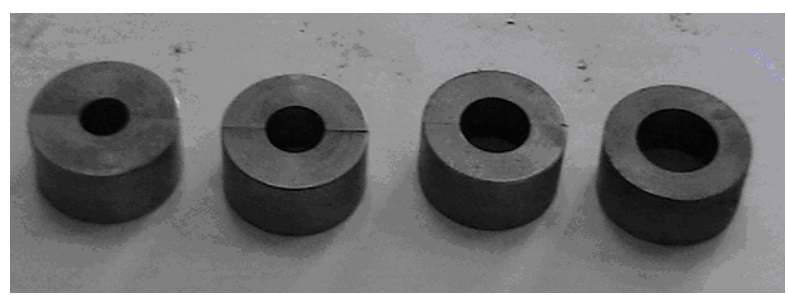

Gambar 3. Dies dengan diameter 22, 19, 16, dan $13 \mathrm{~mm}$.

Pada penelitian ini, seluruh spesimen diannealing dengan merendam spesimen ke dalam air panas $\left(100^{\circ} \mathrm{C}\right)$ selama kira-kira 20 menit. Sebelum digunakan semua perlatan harus dibersihkan dan diberi pelumas untuk memudahkan benda kerja mengalir selama terdeformasi. Empat dies dengan diameter yang berbeda masing-masing $22,19,16$, dan $13 \mathrm{~mm}$ digunakan untuk membandingkan hasil pengaruh gesekan. Gambar 3 adalah empat dies dengan reduksi masing-masing $0.25,0.44,0.6$, dan 0.74 . Pengujian pertama yang dilakukan adalah uji tekan (compression test), dengan tujuan untuk memperoleh diagram tegangan regangan benda kerja yang akan digunakan untuk menentukan properti material dalam simulasi.

Proses simulasi dilakukan dengan software ABAQUS 65.3 SE. Variasi terhadap koefisien gesekan dilakukan untuk mengetahui pengaruh dari perbedaan koefisien gesek antara permukaan yang bersentuhan pada benda kerja dan kontainer serta dies. Pemodelan dengan simulasi ABAQUS dilakukan dengan benda silinder dengan ukuran dan property yang sama dengan yang diperoleh dari eksperimen, dimana sifat plastisitas benda diambil dari data uji tekan. Benda uji dianggap axisymmetric deformable, sedangkan dies, kontainer dan punch dimodelkan sebagai analytical rigid surfaces. Pada pengujian pertama, semua permukaan kontak dianggap terpelumasi dengan baik (frictionless). Penelitian selanjutnya dilakukan dengan memberikan penalty pada koefisien gesek semua permukaan yang kontak. Untuk mengatasi distorsi yang berlebihan selama 
proses ekstrusi maka digunakan teknik adaptive meshing.

\section{HASIL DAN PEMBAHASAN}

Gambar 4 menunjukkan hasil proses ekstrusi pada akhir langkah penekanan hasil eksperimen dan simulasi. Terlihat bahwa benda kerja mengalami distorsi yang berlebihan selama terdeformasi sehingga menimbulkan terjadinya rongga berbentuk seperti pipa kerucut. Perbandingan dilakukan terhadap hasil yang diperoleh dari eksperimen dan simulasi. Dari kedua hasil tersebut dapat dilihat bentuk produk ekstrusi mendekati antara hasil eksperimen dan simulasi.

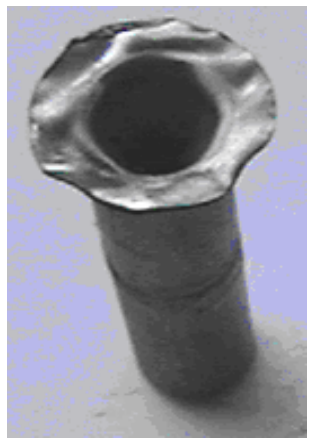

(a)
Hasil penelitian dengan simulasi tentang pengaruh gesekan pada proses ekstrusi menunjukkan bahwa koefisien gesekan cukup besar dalam menentukan besar gaya penekanan. Gambar 5 menunjukkan pengaruh koefisien gesekan antara benda uji dengan bidang penekan dan kontainer terhadap gaya penekanan (punch force) dan langkah penekanan (punch displacement). Penelitian dilakukan dengan menggunakan lima nilai perbedaan koefisien gesekan dengan menggunakan dies dengan reduksi $0.25,0.44,0.6$, dan 0.74 . Hasil penelitian menunjukkan bahwa semakin tinggi koefisien gesekan akan mengakibatkan bertambahnya gaya penekanan yang dibutuhkan selama proses ekstrusi.

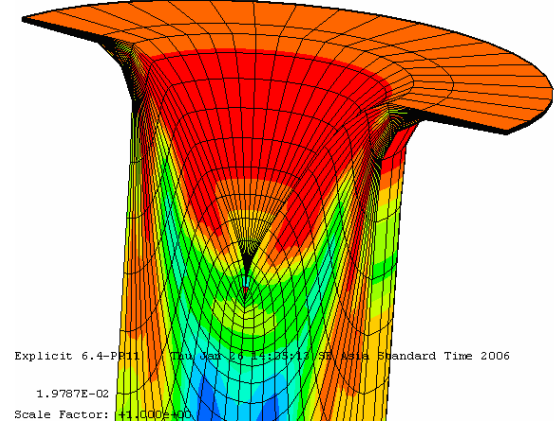

(b)

Gambar 4. Hasil eksperimen (a)dan simulasi (b) pada proses ekstrusi dengan reduksi 0.74

Dari Gambar 5 (a)-(d) berikut juga menunjukkan pengaruh reduksi dan hubungan antara gaya penekanan (punch load) dengan gerakan penekan (punch displacement) pada benda uji selama mengalami proses ekstrusi. Dari ke-empat hasil menunjukkan bahwa dengan pada nilai koefisien gesekan yang sama, bertambahnya reduksi akan makin menambah gaya penekanan. Hal lain yang terlihat adalah karakteristik fase deformasi pada proses ekstrusi yang dimulai dengan proses coining, yaitu proses pemenuhan isi kontainer oleh benda kerja, proses steady state dimana gaya penekanan akan berangsur-angsur menurun seiring dengan berkurangnya panjang benda kerja, dan proses unsteady state dimana permukaan benda kerja mencapai hampir mendekati permukaan dies. Pada zona ini pula terjadi dead metal zone. 


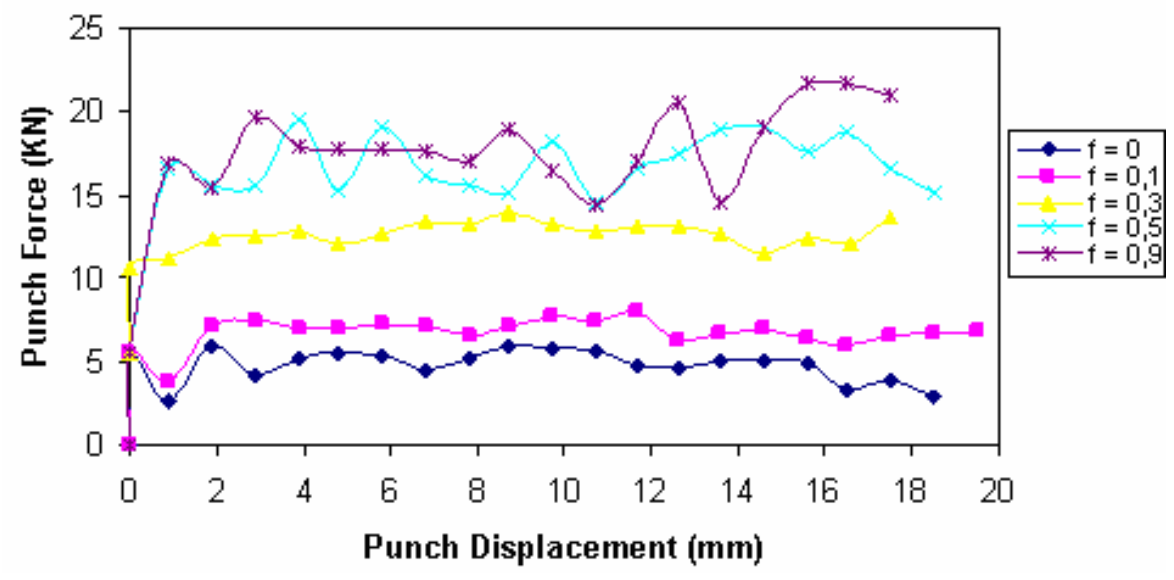

(a)

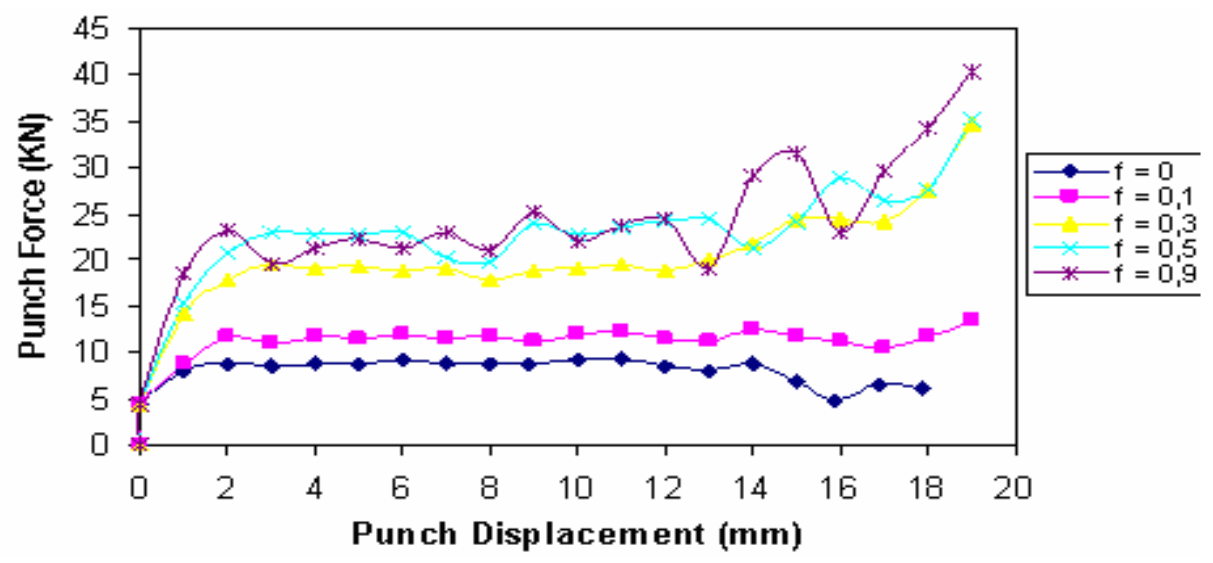

(b)

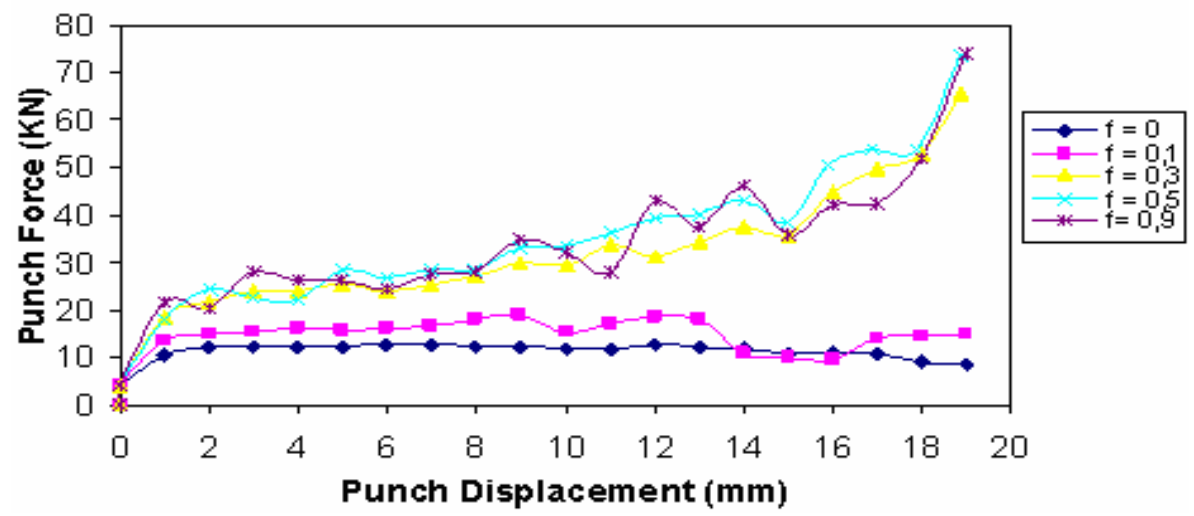

(c) 


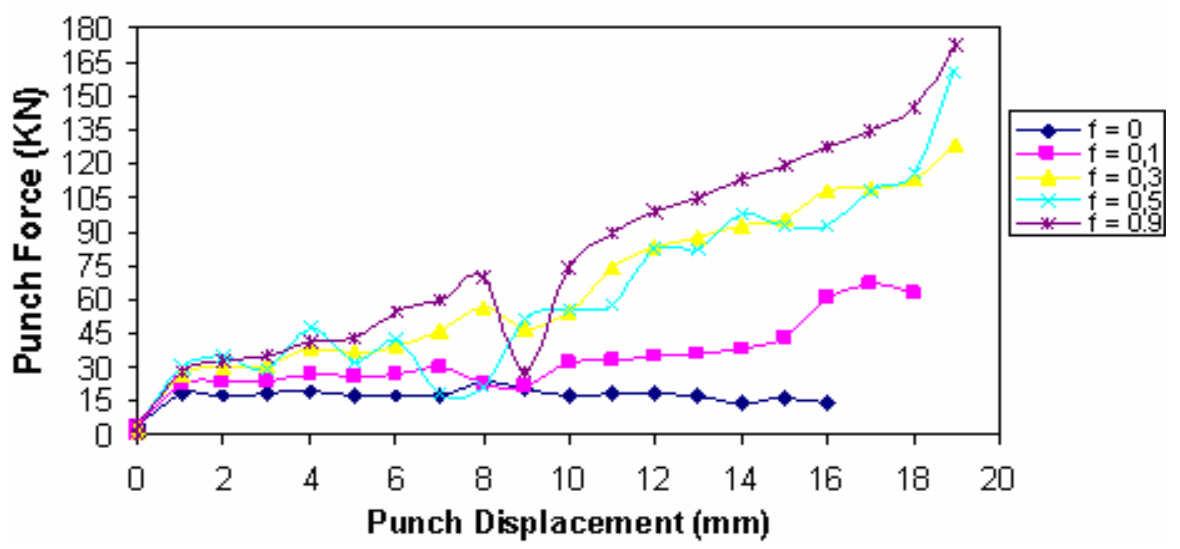

(d)

Gambar 5. Pengaruh koefisien gesekan pada gaya penekanan selama proses ekstrusi dengan reduksi masing-masing (a). 0.25, (b). 0.44, (c). 0.6, dan (d). 0.74

Dari perbandingan antara hasil teori dan hasil eksperimen diperoleh bahwa pada fase steady state, gaya penekanan yang mendekati hasil teori hanya terjadi pada kondisi koefisien gesek yang rendah atau mendekati tidak ada gesekan. Terlihat pada semua grafik bahwa gaya penekanan akan linier pada koefisien gesekan 0.0 dan 0.1 . Sementara pada koefisien gesek yang lebih tinggi yaitu $0.3,0.5$, dan 0.9 gaya penekanan akan berfluktuasi. Hal ini kemungkinan disebabkan oleh kesalahan asumsi yang dilakukan pada proses simulasi.

\section{KESIMPULAN}

Dari hasil pengujian proses ekstrusi dengan cara eksperimen dan simulasi dapat disimpulkan bahwa koefisien gesek sangat mempengaruhi besar gaya penekanan selama proses ekstrusi. Semakin besar koefisien gesekan maka gaya penekanan yang dibutuhkan akan semakin besar pula. Besar gaya penekanan pada proses ekstrusi juga tergantung dari besarnya reduksi benda kerja. 


\section{DAFTAR PUSTAKA}

H.W. Wagener, J. Wolf, 1994, Coefficient of friction in cold extrusion, J. Mater. Process. Technol. 44, 283-291.

T. Nakamura, N. Bay, 1996, FEM simulation of a friction testing method based on combined forward rod-backward can extrusion, Trans. ASME.

T. Nakamura, N. Bay, 1996, FEM simulation of a friction testing method based on combined forward conical can-backward straight can extrusion, Trans. ASME 120.

T.-C. Hsu, C.-H. Lee, 1995, A realistic friction modeling in simple upsetting, Master degree Thesis, Yuan Ze University, Chungli, Taoyuan County, Taiwan.

T.-C. Hsu, Y.-M. Li, 1997, A realistic friction model for computer simulation of extrusion processes, Master degree Thesis, Yuan Ze University, Chungli, Taoyuan County, Taiwan.

G. Shen dkk, 1992, A Method for Evaluating Friction Using a Backward Extrusion - Type Forging, J. Mater. Process \& Technol. 33, 109-123.

M. Bakshi-Jooybari, 2003, A Theoretical and Experimental Study of Friction in Metal Forming by The Use of The Forward Extrusion Process, J. Mater. Process \& Technol. 125-126, 369-374 